\title{
Review of the Pharmacological Treatment of Delirium in the Pediatric Population with Accompanying Protocol
}

\author{
Nathan Lavid M.D. \\ University of California, Irvine \\ Lawrence J. Budner M.D., F.A.A.C.A.P. \\ Children's Hospital of Orange County; Department of Child and Adolescent Psychiatry at the University of \\ California, Irvine
}

Follow this and additional works at: https://jdc.jefferson.edu/jeffjpsychiatry

Part of the Psychiatry Commons

Let us know how access to this document benefits you

\section{Recommended Citation}

Lavid, Nathan M.D. and Budner, Lawrence J. M.D., F.A.A.C.A.P. (2000) "Review of the Pharmacological Treatment of Delirium in the Pediatric Population with Accompanying Protocol," Jefferson Journal of Psychiatry. Vol. 15 : Iss. 1 , Article 3.

DOI: https://doi.org/10.29046/JJP.015.1.002

Available at: https://jdc.jefferson.edu/jeffjpsychiatry/vol15/iss $1 / 3$

This Article is brought to you for free and open access by the Jefferson Digital Commons. The Jefferson Digital Commons is a service of Thomas Jefferson University's Center for Teaching and Learning (CTL). The Commons is a showcase for Jefferson books and journals, peer-reviewed scholarly publications, unique historical collections from the University archives, and teaching tools. The Jefferson Digital Commons allows researchers and interested readers anywhere in the world to learn about and keep up to date with Jefferson scholarship. This article has been accepted for inclusion in Jefferson Journal of Psychiatry by an authorized administrator of the Jefferson Digital Commons. For more information, please contact: JeffersonDigitalCommons@jefferson.edu. 


\title{
Review of the Pharmacological Treatment of Delirium in the Pediatric Population with Accompanying Protocol
}

\author{
Nathan Lavid, M.D. and \\ Lawrence J. Budner, M.D., F.A.A.C.A.P.
}

\begin{abstract}
Objective: To review the current state of pharmacological treatment of delirium in the pediatric population and to derive a treatment protocol from our review.

Method: Medline-assisted search of the literature. Articles pertaining to the pharmacological treatment of delirium in children and adolescents were reviewed. Due to the paucity of articles, studies of treatment guidelines for delirium in the adult population were reviewed. Also presented for reference, are studies of optimal dosing regimens of psychotrophic agents potentially useful in treating pediatric delirium. Our protocol is extrapolated from previously established guidelines for adult treatment meshed with the current knowledge presented in the literature pertaining to children and adolescents.

Results: Review revealed only one retrospective study evaluating the pharmacological treatment of delirium in children and adolescents. One anecdotal report of risperidone successfully treating delirium is presented. Intravenous haloperidol is the mainstay of pharmacological treatment in medically ill adults and haloperidol has a long history of safety and efficacy in children and adolescents.

Conclusion: Use of intravenous haloperidol with titration to an efficacious dose would be the first line approach to treat symptoms of delirium in the pediatric population. However the lack of data and systematic analysis in the literature demonstrates an acute need for structured research in this area.

The aim of this article is to review the current state of pharmacological treatment of delirium in the pediatric population and to derive a treatment protocol from our review. There is a conspicuous lack of research in this area and there are no previous reviews in the literature. To complete our objective, we present the current state of treatment of delirium in adults, along with the limited amount of literature pertaining to delirium in children and adolescents. For reference, current pediatric pharmacological dosing regimens are presented. Our protocol is derived from an extrapolation of guidelines for adult treatment meshed with the current knowledge presented in the literature pertaining to children and adolescents.
\end{abstract}


Delirium is a transient mental syndrome of acute onset, characterized by global impairment of cognitive functions, a reduced level of consciousness, attentional abnormalities, changes in psychomotor activity and a disordered sleep-wake cycle (1). The concept of delirium has been recognized for approximately 2500 years (2). The diagnostic criteria have evolved to several core features (Table 1) coupled with specifiers that distinguish etiology, i.e. due to a general medical condition, due to multiple etiologies, for substance intoxication, for substance withdrawal and causes not otherwise specified (3).

The average prevalence of delirium in the general hospital population is $20 \%$ (4). Although the pediatric population has not been well studied, Antoon et al. (5) reported that approximately $14 \%$ of hospitalized burn patients had delirium. These estimates may be low given that there is a high rate of misdiagnosis with delirium. Armstrong et al., (6) reported that $46 \%$ of hospitalized adults with delirium were misdiagnosed, i.e. a delirious patient was diagnosed with another condition (depressive disorder, psychotic disorder, no diagnosis, etc.). Also the expression of delirium in children can vary from adults, e.g. magical thinking, mania or regression (7), making the diagnosis even more difficult for the treating physicians. The transient nature of delirium also adds to the difficulty with diagnosis.

The consequences of altered consciousness can be quite deleterious to the patient, e.g. pulling out catheters and other self-injurious behavior and has been shown in adult populations to increase mortality $(4,8)$. Thus, early recognition of the delirium with appropriate treatment is essential.

The first step in the treatment of delirium is to identify any causal condition. The most common causes involve intoxication with exogenous substances, systemic or cerebral disease and withdrawal from substances of abuse (1). However the underlying etiology may not be easily distinguished. This can be quite difficult in that the delirium may be caused by multiple etiologies and individually may not be considered significant by the treating physicians. In the interim of diagnostic work-up, treatment should include reassurance and reorientation. If this is not sufficient, pharmacological intervention is used as an adjunct for symptom management and antipsychotic medication has been the mainstay of treatment (9).

\section{TABLE 1.}

\section{Diagnostic Criteria for Delirium}

A) Disturbance of consciousness (i.e., reduced clarity of awareness of the environment) with reduced ability to focus, sustain, or shift attention.

B) A change in cognition (such as memory deficit, disorientation, language disturbance) or the development of a perceptual disturbance that is not better accounted for by a preexisting condition, established, or evolving dementia.

C) The disturbance develops over a short period of time (usually hours to days) and tends to fluctuate during the course of the day.

Diagnostic and Statistical Manual of Mental Disorders, Fourth Edition. Washington, DC, American Psychiatric Association, 1994. 


\section{TYPICAL ANTIPSYCHOTICS}

\section{Haloperidol}

Haloperidol, a butyrophenone neuroleptic that can be administered via enteral, intramuscular or intravenous routes, is a well-documented safe treatment of delirium symptoms in adults (9). It is a high potency neuroleptic with low potential for anticholinergic, antialpha-adrenergic and autonomic effects and is unlikely to exacerbate delirium $(9,10)$. It alleviates aggression, psychomotor agitation, hallucinations and delusions (10) and is considered the preferred agent for treating delirium in the critically ill adult (11). The intravenous route has a safe side-effect profile and has a reduced incidence of extrapyramidal reactions when compared to oral administration $(10,12)$. The intravenous route is also the quickest way to initiate treatment, i.e. peak serum levels are reached soon after administration, whereas the enteral and IM routes may take up to several hours (10). Also, parental doses of haloperidol have $100 \%$ bioavailability (compared to the approximate $60 \%$ bioavailability of oral dosing), and are dosed approximately one-half that of oral doses (10). Initial bolus intravenous doses range from 0.5 to $20 \mathrm{mg}$ (4) and mega-doses (>1000 mg/day) have been given safely in cases of refractory delirium $(13,14)$. Specific guidelines for treating the delirious adult patient vary in the literature. Shapiro et al. (11) outline a starting dose of 2 to $10 \mathrm{mg}$ intravenously with the dosage repeated every 2 to $4 \mathrm{hrs}$. Maintenance dosing regimens have been proposed of continuing intravenous haloperidol at $50 \%$ of the dose that controlled symptoms with rapid dose reduction (15) or administering low dose (0.5 to $3 \mathrm{mg}$ ) oral haloperidol (16).

Antipsychotic medications though commonly prescribed to children are not as well investigated. The Food and Drug Administration (FDA) advertising guidelines for haloperidol indicate use in (i) management of psychosis, (ii) control of tics and vocal utterance in Tourette's disorder, (iii) severe behavioral problems in children marked by combativeness and/or explosive hyperexcitable behavior (that is not accountable to immediate provications) and short-term treatment of ADHD (17). The lower age limit is 3 years with dose limits of $0.15 \mathrm{mg} / \mathrm{kg} / \mathrm{day}$ for psychosis and $0.075 \mathrm{mg} / \mathrm{kg} /$ day for behavior disorders and Tourette's disorder (17). However, review of the literature by Findling et al. (18) reveals that haloperidol has also been used in treating mood disorders, pervasive developmental disorder, mental retardation, conduct disorder, anorexia nervosa and personality disorders in children and adolescents. Children have been found to respond to lower neuroleptic plasma levels (19) and the dosing of haloperidol, in the pediatric population, tends to be lower and more conservative than in adults. The average optimal dose range of haloperidol for the schizophrenic pediatric population is 0.02 to $0.12 \mathrm{mg} / \mathrm{kg} / \mathrm{day}$ [0.5 to $3.5 \mathrm{mg} / \mathrm{day}]$ (20).

The most common short-term side effects of haloperidol in children and adolescents are sedation and extrapyramidal symptoms (EPS) (21). EPS are rarely observed in preschool-aged children, but are more common in school age and adolescents (19). The sedation is dose-related and can be relieved by a reduction in dose (21). Extrapyramidal symptoms are not dose-dependent and are sudden in onset (9). Most 
EPS can be resolved with a reduction in dose and/or management with anticholinergics (20). Also, with short-term haloperidol use, the possibility of neuroleptic malignant syndrome (NMS) should be considered. NMS is a potentially fatal complication that occurs at all ages and starts within a few days of initiating neuroleptic treatment. Fortunately the syndrome is rare $-0.4 \%$ to $0.5 \%$ of newly treated patients (22). Also of concern, in critically ill adults, is an association of prolongation of the QTc interval (QT interval corrected for heart rate) with the possibility of ensuing torsades de pointes (a polymorphous ventricular tachycardia) with intravenous butyrophenone therapy $(23,24)$. Lawrence \& Nasraway (23) recommend electrocardiogram (EKG) monitoring in critically ill patients, with discontinuation or reduction of dose if the QTc interval lengthens by $25 \%$ or more over baseline. Cardiac conduction abnormalities associated with butyrophenone administration in children and adolescents have not been reported in the literature and the implications of this possible adverse effect are not known.

There has only been one study revealed in our search that addressed the use of neuroleptics to treat delirium in children and adolescents. Brown et al. (25) studied the use of haloperidol in 30 pediatric burn patients to treat agitation and delirium. Here the short term use of haloperidol (longest period of treatment was three months) had an incidence of adverse reactions of $0.47 \%$ (an episode of decreased consciousness and an episode of hypotension after 429 doses administered). The mean dose of haloperidol used was $0.047 \mathrm{mg} / \mathrm{kg}$ with the mean number of doses given at 14. The largest cumulative dose administered over a 24-hour period was 0.455 $\mathrm{mg} / \mathrm{kg}$. The largest number of doses given over a 24-hour period was six. With intravenous administration of haloperidol, the onset of effect was within thirty minutes. They reported higher efficacy via the intravenous route and found no contraindications to using haloperidol to treat agitation in children.

\section{Droperidol}

Droperidol is another butyrophenone neuroleptic that has also been used successfully to treat delirium in adults $(26,27)$. It is available for intramuscular or intravenous administration (17). Compared to haloperidol, it has a more rapid onset of action, is more sedating and is more apt to cause hypotension $(9,26)$. Its use to treat delirium in the pediatric population has not been reported. However, droperidol has been studied for the management of acute agitation and aggression in children and adolescents. Joshi et al. (28) reported use of intramuscular droperidol in a children's inpatient unit to control extreme aggression and violent behaviors. Over a period of three years, twenty-six children (mean age of 9.14) received a one time dose (except two boys who were refractory after 30 minutes and required another dose) of droperidol to induce sedation. The amount of droperidol used, in the children, was based on body weight: $<75 \mathrm{lbs} .=1 / 4 \mathrm{cc} ; 75$ to $125 \mathrm{lbs} .=1 / 2 \mathrm{cc} ; 125$ to $150 \mathrm{lbs} .=3 / 4 \mathrm{cc}$; $>150 \mathrm{lbs} .=1 \mathrm{cc}$ and the mean dose used was $0.437 \mathrm{cc}(1 \mathrm{cc}=2.5 \mathrm{mg})$. The use of droperidol was deemed efficacious and produced only mild EPS in two of the children. 


\section{ATYPICAL ANTIPSYCHOTICS}

The emergence of the new atypical antipsychotics has allowed a greater armament of pharmacological choices in treating many psychiatric conditions in children. The new medications have shown benefit without some of the extrapyramidal side effects of the conventional antipsychotics (29-31). The atypical antipsychotics have been used in children and adolescents in cases of schizophrenia (32,33), autism (34), and pervasive developmental disorder (35).

Dosing regimens of the atypical antipsychotics in children and adolescents vary in the literature. Risperidone and olanzapine are only administered enterally. Risperidone was FDA approved in 1993 with a dosing range of 2 to $16 \mathrm{mg}$ /day (17). In children with psychotic disorders, the optimal clinical response was found at mean daily dose of $5.93 \mathrm{mg}$ (32). In autism, response was with a mean dose of $1.3 \mathrm{mg} /$ day (34). A study of children and adolescents with pervasive developmental disorder showed improvement of symptoms with a mean dose of $2.7 \mathrm{mg} /$ day (35). The FDA approved olanzapine in 1996 with a dosing range of 5 to $20 \mathrm{mg} /$ day (17). In adults, olanzapine has been found to posses antipsychotic properties with an optimal dosing range of 2.5 to $15 \mathrm{mg} /$ day (30). Olanzapine has not been extensively studied in children, however, a pilot study of childhood-onset schizophrenia showed efficacy at a mean dose of $17.5 \mathrm{mg} /$ day (36). Also a study of children, adolescents and adults with pervasive developmental disorders showed clinical improvement with a mean dose of $7.8 \mathrm{mg} /$ day (37).

The literature does not document many short-term contraindications of the newer antipsychotics in children and adolescents. Risperidone has been shown to cause mild sedation and EPS in a population of adolescents with schizophrenia, with the expression of EPS inversely proportionate to the rate of titration of the risperidone (32). There has been a case report of olanzapine (dosed $7.5 \mathrm{mg} /$ day over a two to three week period) inducing mania in a sixteen year old male (38). Also, as with the typical antipsychotics, there is a risk of NMS in the newer antipsychotics. Sharma et al. (39) report of risperidone-induced NMS in an adolescent male.

There have been no systematic studies of the efficacy of treating delirium in children or adults with the new atypical antipsychotics. However Sipahimalani and Masand (40) report of a sixty year old male and a fourteen year old male in whom delirium was successfully treated with low doses of risperidone. The adolescent responded to $1 \mathrm{mg}$ of risperidone at bedtime without side effects.

\section{ADJUNGT MEDICATIONS}

The antipsychotic medications are considered efficacious in treating delirium (41). Polypharmacy has been discouraged in children (42). Also, iatrogenic induced delirium is common. However a few medicines have been used to augment antipsychotics in treating delirium and there may be cases where adjunctive medicine is deemed appropriate. 
population, the use of haloperidol with slow titration to an efficacious dose would seem to be the logical first line approach in treating delirium. If a delirious child with available intravenous access were hospitalized, then intravenous route would be recommended due to the rapid onset of action and the lower incidence of EPS. If the child does not already have intravenous access, clinician judgement would dictate if the severity of symptoms of the delirium require rapid infusion of medicine. The need for EKG monitoring, with intravenous butyrophenone neuroleptic administration in children and adolescents, is questionable. However, we recommend a conservative approach with baseline EKG acquisition followed by cardiac monitoring or daily QTc interval testing. If the QTc interval increases $25 \%$ over baseline, then the neuroleptic dose should be discontinued or lowered. The clinical use of droperidol in children is not as well investigated compared to haloperidol. Haloperidol has a longer history of use in the pediatric population, however we consider droperidol an adequate alternative.

There has only been one case report of an atypical antipsychotic (risperidone) used for the treatment of delirium in an adolescent. Atypical antipsychotics have shown efficacy in treating a number of psychiatric conditions in children and adolescents, with minimal short-term side effects. Controlled studies of the atypical antipsychotics in treating delirium are warranted to establish their efficacy.

These recommendations are based on assumptions from adult populations and the limited data available pertaining to children and adolescents. This protocol is not meant for adherence as a protocol proposed from controlled study; rather it is proposed as template for further study and to suffice as other techniques and management are postulated. The lack of data and systematic analysis in the literature pertaining to the treatment of delirium in children and adolescents demonstrates an acute need for structured research in this area.

\section{REFERENCES}

1. Lipowski ZJ: Delirium: Acute Confusional States. New York, Oxford Press 1990, pp 41, 109-140.

2. Lipowski ZJ: Delirium: how its concept has developed. Int Psychogeriatr 1991; Winter: 3(2): 115-120.

3. Diagnostic and Statistical Manual of Mental Disorders. Fourth edition, (DSM-IV). American Psychiatric Association. Washington, DC 1994.

4. Trzepacz PT: Delirium: Advances in Diagnosis, Pathophysiology, and Treatment. Psychiatr Clin North Am 1996; 19(3): 429-448.

5. Antoon AY, Volpe JJ, Crawford JD: Burn Encephalopathy in Children. Pediatrics 1972; 50(4): 609-616.

6. Armstrong SC, Cozza KL, Watanbe KS: The Misdiagnosis of Delirium. Psychosomatics 1997; 38: 433-439.

7. Prugh DG, Wagonfeld S, Metcalf D, et al: A Clinical Study of Delirium in Children and Adolescents. Psychosom Med 1980; 42(1:II Suppl): 177-195.

8. Van Hemert AM, van der Mast RC, Hegneveld MW, et al: Excess mortality in general hospital patients with delirium: a 5-year follow-up of 519 patients seen in psychiatric consultation. J Psychosom Res 1994; 38(4): 339-346. 
9. Fish DN: Treatment of delirium in the critically ill patient. Clin Pharm 1991; 10: 456-466.

10. Settle EC, Ayd FJ: Haloperidol: A Quarter Century of Experience. J Clin Psychiatry 1983; 44(12): 440-448.

11. Shapiro BA, Warren J, Egol AB, et al: Practice parameters for intravenous analgesia and sedation for adult patients in the intensive care unit: An executive summary. Crit Care Med 1995; 23(9): 1596-1600.

12. Menza MA, Murray GB, Holmes VF, et al: Decreased extrapyramidal symptoms with intravenous haloperidol. J Clin Psychiatry 1987; 48(7): 278-280.

13. Levenson JL: High-Dose Intravenous Haloperidol for Agitated Delirium Following Lung Transplantation. Psychosomatics 1995; 36(1): 66-68.

14. Riker RR, Fraser GL, Cox PM: Continuous infusion of haloperidol controls agitation in critically ill patients. Crit Care Med 1994; 22(3): 433-440.

15. Adams F: Emergency Intravenous Sedation of the Delirious, Medically Ill Patient. J Clin Psychiatry 1988; 49(suppl 12): 22-26.

16. Gelfand SB, Indelicato J, Benjamin J: Using Intravenous Haloperidol to Control Delirium. Hosp Comm Psychiatry 1992; 43(3): 215.

17. Physicians' Desk Reference. Fifty second edition. Medical Economics Company. Montvale, NJ, 1998; pp 546, 1309-1313, 1512-1516, 1997-1999.

18. Findling RL, Grcevich SJ, Lopez I, et al: Antipsychotic Medications in Children and Adolescents. J Clin Psychiatry 1996; 57 (suppl 9): 19-23.

19. Teicher MH, Glod CA: Neuroleptic Drugs: Indications and Guidelines for Their Rational Use in Children and Adolescents. J Child Adolesc Psychopharmacol 1990; 1(1): 33-56.

20. Spencer EK, Kafantaris V, Pandron-Gayol MV, et al: Haloperidol in Schizophrenic Children: Early Findings From a Study in Progress. Psychopharmacol Bull 1992; 28(2): 183-186.

21. Serrano AC: Haloperidol-Its Use in Children. J Clin Psychiatry 1981; 42(4): 154-156.

22. Shalev A, Muntiz H: The neuroleptic malignant syndrome: agent and host interaction. Acta Psychiatr Scand 1986; 73: 337-347.

23. Lawrence KR, Nasraway SA: Conduction disturbances associated with administration of butyrophenone antipsychotics in the critically ill: a review of the literature. Crit Care Pharmacy 1997; 17(3): 531-537.

24. Sharma ND, Rosman HS, Padhi D, et al: Torsades de Pointes Associated With Intravenous Haloperidol in Critically Ill Patients. Am J Cardiology 1998; 81: 238-240.

25. Brown RL, Henke A, Greenhalgh DG, et al: The Use of Haloperidol in the Agitated, Critically Ill Pediatric Patient with Burns. J Burn Care Rehabil 1996; 17: 34-38.

26. Resnick M, Burton BT: Droperidol vs. Haloperidol in the Initial Management of Acutely Agitated Patients. J Clin Psychiatry 1984; 45: 298-299.

27. Thomas H, Schwartz E, Petrilli R: Droperidol versus Haloperidol for Chemical Restraint of Agitated and Combative Patients. Ann Emerg Med 1992; 21 (4): 407-413.

28. Joshi PT, Hamel L, Joshi A, et al: Use of Droperidol in Hospitalized Children. J Am Acad Child Adolesc Psychiatry 1998; 37(2): 228-230.

29. Casey DE: The Relationship of Pharmacology to Side Effects. J Clin Psychiatry 1997; 58(suppl 10): 55-62.

30. Kando JC, Shepski JC, Satterlee W, et al: Olazapine: A New Antipsychotic Agent with Efficacy in the Management of Schizophrenia. Ann Pharmacother 1997; 31: 1325-1334.

31. Toren P, Laor N, Weizman A: Use of Atypical Neuroleptics in Child and Adolescent Psychiatry. J Clin Psychiatry 1998; 59(12): 644-656. 
32. Grcevich SJ, Findling RL, Rowane WA, et al: Risperidone in the treatment of children and adolescents with schizophrenia: a retrospective study. J Child Adolesc Psychopharmacol 1996; Winter; 6(4): 251-257.

33. Masi G: Atypical neuroleptics in the treatment of early onset schizophrenia. Panminerva Med 1997; 39(3): 215-221.

34. Nicolson R, Awad G, Sloman L: An open trial of risperidone in young autistic children. J Am Acad Child Adolesc Psychiatry 1998; 37(4): 372-376.

35. Perry R, Pataki C, Munoz-Silva DM, et al: Risperidone in children and adolescents with pervasive developmental disorder: pilot trial and follow-up. J Child Adolesc Psychopharmacol 1997; 7(3): 167-179.

36. Kumra S, Jacobsen LK, Lenane M, et al: Childhood-onset schizophrenia: an open-label study of olanzapine in adolescents. J Am Acad Child Adolesc Psychiatry 1998; 37(4): 377-385.

37. Potenza MN, Holmes JP, Kanes SJ, et al: Olanzapine treatment of children, adolescents, and adults with pervasive developmental disorders: an open-label pilot study. J Clin Psychopharmacol 1999; 19(1): 37-44.

38. London JA: Mania Associated with Olanzapine. J Am Acad Child Adolesc Psychiatry 1998; 37(2): 135-136.

39. Sharma R, Tappler B, Ng YK, et al: Risperidone-induced neuroleptic malignant syndrome. Ann Pharmacother 1996; 30(7-8): 775-778.

40. Sipahimalani A, Masand PS: Use of Risperidone in Delirium: Case Reports. Ann Clin Psychiatry 1997; 9(2): 105-107.

41. Breitbart W, Marotta R, Platt MM, et al: A Double-Blind Trial of Haloperidol, Chlorpromazine, and Lorazepam in the Treatment of Delirium in Hospitalized AIDS Patients. Am J Psychiatry 1996; 153(2): 231-237.

42. Zavodnick JM: Combined drug therapy debate (continued) [letter; comment]. J Am Acad Child Adolesc Psychiatry 1997; 36(1): 1-3.

43. Bowen JD, Larson EB: Drug-induced cognitive impairment. Defining the problem and finding solutions. Drugs Aging 1993; 3(4): 349-357.

44. Kaplan CA, Hussain S: Use of Drugs in Children and Adolescent Psychiatry. Brit J Psychiatry 1995; 166: 291-298.

45. Carrey NJ, Wiggins DM, Milin RP: Pharmacological Treatment of Psychiatric Disorders in Children and Adolescents: Focus on Guidelines for the Primary Care Practitioner. Drugs 1996; 51 (5): 750-759.

46. Hassan E, Fontaine DK, Nearman HS: Therapeutic Considerations in the Management of Agitated or Delirious Critically Ill Patients. Pharmacotherapy 1998; 18(1): 113-129. 